\section{OPEN ACCESS}

\title{
Learning to teach and play futsal using digital tablets: \\ What knowledge do sports science students mobilize?
}

Authors' contribution:

A) conception and design of the study

B) acquisition of data

C) analysis and interpretation of data

D) manuscript preparation

E) obtaining funding

Received: 20.01.2021

Accepted: 04.05.2021

\author{
Maël Le Paven*1A-D (D, Rebecca Clayton ${ }^{2 A-D}$ (D), \\ Gilles Kermarrec ${ }^{1 \mathrm{~A}-\mathrm{E}}$ \\ ${ }^{1}$ University of Western Brittany, Brest, France \\ ${ }^{2}$ IMT Atlantique Bretagne Pays de la Loire, Brest, France
}

*Correspondance: Maël Le Paven, Faculté des Sciences du Sport et de l'Education 20, avenue Victor Le Gorgeu - CS 93837 - 29238 Brest cedex 3, France; email: mael. lepaven@univ-brest.fr

\begin{abstract}
There is little research on the knowledge mobilized by sports science students when they learn to play a sport by learning to teach it. This study focuses on the benefits of using digital tablets to foster this learning during a university teaching module in futsal with students in the second year of a sports science bachelor's degree. We compare the knowledge mobilized by these students during self-confrontation interviews (based on video recordings of the sessions), game situations, reciprocal coaching and debates of ideas. We then identify the nature of this knowledge and the strategies for its mobilization in context using a framework mainly based on didactics in physical education (Amade-Escot, 2006; Armour, 2011) and on pedagogical content knowledge studies (Shulman, 1986). The students were divided into two experimental conditions following the same pedagogical curriculum. The students in condition 1 used digital tablets to film themselves, tag videos and discuss the recordings. The students in condition 2 did not use tablets. The interviews were conducted twice during the teaching module: first during period 1 (beginning of the module) and then during period 2 (end of the module). The results show that students in condition 1 were more likely to mobilize shared knowledge, make decisions through cooperation and even devolve the construction of tactical reasoning and knowledge by their peers following the didactic approach of the faculty teacher as early as period 1 . This promoted access to the construction and meaning of teaching and learning content. These results are discussed in light of the current challenges within educational systems and of the joint development of interactional skills for learning to cooperate and even to teach.
\end{abstract}

Keywords: Student education, sport pedagogy, digital technologies, team sports teaching, cooperative learning

\section{Introduction}

Most university curricula in sports science integrate practical modules into student teacher (ST) education, which is led by faculty teachers (e.g., Deenihan, Young, \& McPhail, 2011). By combining the varied experiences of players, participants (Kinchin et al., 2005) and teachers with those of their classmates (Collier, 1998), practical team sports modules facilitate the understanding of the game, teamwork and tactics (Carlson, 1995). Through long modules and multiple co-observations, according to Oslin et al. (2001), STs construct effective links between their 
pedagogical content knowledge (PCK; Shulman, 1986) and their subject matter knowledge (SMK) based on their experience as players, students and teachers (Rollnick \& Mavhunga, 2016).

However, few studies focus on the specific links between SMK and PCK constructed through this combination of roles.

This study deals with the mobilization of these two types of knowledge by students in the second year of a sports science bachelor's degree who will go on to become sports teachers or coaches. We refer to them as student teachers/coaches (STCs). We focus on how these STCs learn to play futsal and teach it to their classmates with or without the use of digital tablets.

The use of digital tablets as a tool is becoming more and more widespread in sports science teaching modules, but the didactic implications of this pedagogical use at universities still requires analysis. The rise of new technologies for education directly affects the training of teachers, increasingly transforming their role into that of "knowledge facilitators" (European Parliamentary Research Service, 2020).

Furthermore, as is shown in the literature review by Moore, Bullough, Goldsmith, and Edmonson (2014), futsal, a sport that is rarely practiced or studied compared to other team sports such as football, is nevertheless often used as a "tool for developing technical and tactical behaviors in young footballers" (p. 113). Its educational integration into vocational training in higher education institutions is advocated by Storchevoy et al. (2013) due to its ability to develop attentional, emotional and initiative control skills.

These findings are supported by other studies (e.g., Moreira et al., 2013; Gomes et al., 2008) on the appropriateness of using futsal to improve tactical and team decision-making skills in a very physically (Castagna et al., 2009) and emotionally (Geisler \& Kerr, 2007) intense sport where players have to think quickly to make good judgements. Studies by Polidoro et al. (2013) and Travassos et al. (2012) show in this respect that regular video autoscopy of players has a positive impact on the stabilization of techniques and tactical patterns. In addition, players' choices of spatial distribution patterns depend on the interactional behaviors they construct (Fonseca et al., 2012). This leads us to question the role of discussions between STCs in their tactical choices, using tablets for this purpose.

That is why the STCs from the experimental group (condition 1 - see Materials and methods) were invited to use tablets to film one another playing the sport and then discuss the sequences, with the aim of improving futsal playing, learning and teaching.

This study focuses on the content knowledge mobilized by the STCs in the two conditions (with a tablet vs. without a tablet). We therefore consider the knowledge mobilized to learn, teach and play futsal, integrating didactic experiences, challenges and effects (Sensevy, 2014). This study will address the following questions relating to the tablet as a mediating tool furthering a didactic project developed within the teams of STCs: How does it contribute to this development? What is its impact on the roles taken on by STCs and the knowledge mobilized? What is its impact on interactions within groups of STCs? How is it integrated into the teaching module?

\section{Literature review and theoretical framework}

\section{Use of digital tablets for STC education in team sports}

Debates of ideas and reciprocal coaching are often set up in team sport teaching in order to help students develop knowledge of objectives and content (Wallhead \& Dyson, 2016). However, there is little research on how preservice teachers use the combination of practical and teaching situations to collaboratively learn how to teach (Stran \& Curtner-Smith, 2010). The study by Deenihan, Young, and McPhail (2011) focuses on preservice physical education teacher education during long sport education curricula. They emphasize STCs' need for many opportunities to observe each other as teachers during practical lessons in order to effectively develop PCK and SMK.

Using self-video feedback, it is easier to identify the knowledge mobilized (Rollnick et al., 2008) to teach in context (Kagan, 1992). Self-video feedback can serve STCs' pedagogical and didactic training objectives provided that they are guided effectively on the relevant elements to be observed. This condition is well documented in the literature on preservice teachers (Fuller \& Manning, 1973). The effectiveness of self-video feedback depends on its ability to show preservice teachers the effects of teaching on student behavior (Sargent, 2018). It also depends on the ability of this type of device to link these effects to the specifics of the subject being taught and to what teachers know about adapting pedagogical content to transform students' behavior (Carter, 1990).

Using specifically designed video analysis software, users can adapt their analysis to the practices taught, highlighting relevant elements to be observed by "tagging" the video stream (Koekoek et al., 2018). The ergonomics of analysis software thus offer new affordances in the learning environment thanks to digital technologies, allowing for more complex pedagogical reasoning (Webb \& Cox, 2004). It is therefore useful for faculty teachers to train 
STCs in the pedagogical and didactic potential of such tools. Koehler and Mishra (2009) characterize the knowledge that allows the contextualized use of this potential as technological pedagogical content knowledge (TPACK).

In the present study, the curriculum requires students to alternate roles regularly (player, observer, teacher/ coach) while using such tools. Structuring the interdependence of these roles is key to success and enables users to build the necessary content in order to adopt them fully (Wallhead \& Dyson, 2016). The aim here is to promote cooperative learning through these different roles within the same team, investigating problems at different times (debates of ideas, reciprocal coaching, etc.).

Reduced game situations (with fewer players than in a full team; Gréhaigne et al., 2005) aim to highlight tactical and organizational problems, which can be useful for matches. This is in line with the findings of the small-sided futsal game experiments conducted by Almeida, Ferreira, and Volossovitch (2013) and by Frencken et al. (2013), which show that these kinds of situations develop the speed and efficiency of (mainly offensive) interactions and actions. This reinforces the constraints of individual and collective tactical and organizational problem-solving, which are typical in futsal and which require quick decision-making (e.g., Moreira et al., 2013; Gomes et al., 2008).

These choices can be discussed during debates of ideas. The "sense of the game" (what it takes to understand the right decisions for action; Gréhaigne et al., 2005) is then built by recognizing tactical configurations and similar decisions between reduced game situations and matches (Hastie \& Curtner-Smith, 2006), which is facilitated by the use of the tablet. Sharing common meanings and knowledge then connects the meaning of situations and the meaning of others as providers and seekers of help (Gillies \& Ashman, 1996). The sense of cooperation in game play is thus closely linked to how it is taught and learned (Wallhead \& Dyson, 2016). Decisions and pedagogical and didactic knowledge are therefore co-constructed and connected within the collaborative learning situations.

This connection is a strong argument in favor of problem-solving situations fostering the identification and experimentation of strategic teaching and learning choices using tablets. We are interested here in situations devolving the regulation of these choices into joint action (Sensevy, 2014). This type of situation reinforces the willingness to try new teaching strategies (Guskey, 1988). In turn, this stimulates the development of SMK and PCK by encouraging STCs to re-examine their knowledge from multiple perspectives and possible decisions (Nespor, 1987), both individually and collectively. In collective learning situations, this development of joint attention (Eilan et al., 2005) to the object of others' attention (Sensevy, 2014) is promoted by the time for collective dialogue between situations (Gréhaigne et al., 2005). This raises awareness of the different components of PCK, which expands the understanding of them (Stein \& Wang, 1988).

\section{Complementarity of STCs'knowledge using a digital tablet}

The PCK framework (Shulman, 1986) was developed with teacher training in mind. It is essentially the question of identifying the knowledge constructed about pedagogical content in order to teach it. As this knowledge is highly contextualized (Rowan et al., 2001), access to it is facilitated by the use of self-video feedback (Rollnick et al., 2008). The PCKnowing framework (Cochran et al., 1993) considers the construction of PCK in a dynamic integration of the different knowledge objects necessary for this construction (Ingersoll, Lux, \& Jenkins, 2014).

According to Magnusson et al. (1999), this integration involves making choices in order to reconstruct the understanding of one's own knowledge and that of others in order to adapt to new situations. This justifies our interest in this reconstruction of knowledge through individual and collective reflection in and on action (Schön, 1983, 1987). This is a strong argument in favor of alternating periods of action and collective reflection in situations that encourage joint inquiry of the problems to be solved. This argument was notably put forward by Gréhaigne et al. (2005) in team sports didactics. However, little research links the study of PCKs and the analysis of didactic interactions within teaching-learning collectives (Cross, 2010).

In the tradition of didactic analysis in physical education (e.g., Amade-Escot, 2006; Armour, 2011), the inquiry about the conditions for the acquisition and transmission of disciplinary knowledge holds an important place.

Teaching content is determined based on this inquiry. This content is designed to guide students to discover and actively appropriate the means to succeed (Brousseau, 1997). This discovery can be facilitated thanks to the tablets' "tagging" function (Koekoek et al., 2018). The PCK is then updated to include knowledge about the cues identified through the students' investigation of the issues at hand and the solutions that make it possible to solve them. This principle of devolution of the problems to be solved here at the heart of reduced game situations is typical of the didactic contract (Brousseau, 1997). This contract shapes teachers' and students' mutual expectations and strategies. Thus, students' learning strategies are based on their investigation of teacher guidance strategies with regard to the disciplinary specificity of acquisition, and vice versa. Sensevy (2014) discussed the complementary practical epistemologies of teachers and students as theories of practice mobilizing knowledge to learn and teach. This 
complementarity is at the heart of a teaching module based on the ability of the STC to transpose this knowledge into the alternating roles of teacher and student.

Although this alternation is common in teaching modules in sports science at universities, the development and articulation of SMK and PCK among student teachers in this type of module is rarely studied (Deenihan, Young, \& McPhail, 2011). The need to both learn together to play and to teach others how to play redefines the classic teacher and student positions that STCs can take within the didactic system (Brousseau, 1997). Joint inquiry on knowledge for participation and teaching should lead to further investigation of the content necessary to articulate these two dimensions within the framework of both didactic and epistemic cooperation (Joffredo-Lebrun et al., 2018).

The aim of this study is to investigate the links between SMK and PCK for STCs. We were interested in the knowledge emanating from the simultaneous discovery of futsal learning content (through the role of the learner), pedagogical content facilitating this learning (through the role of STC) and conditions facilitating the learning of this pedagogical content (through the role of the faculty teacher).

The exact nature of this knowledge has rarely been explored in the literature. This knowledge also concerns the use of a technological tool (digital tablet) to foster acquisition of this content. The TPACKing framework uses TPACK as a starting point for analyzing the way teachers construct knowledge (Olofson, Swallow, \& Neumann, 2016). The authors explain that it allows researchers to consider the knowledge of the pedagogical content involved in the specific use of this digital tool in order to teach and learn. The aim here is to identify the specific content of this knowledge and its direct link with PCK and SMK.

\section{Hypotheses}

It was expected that the "tagging" function of the digital tablet could foster the construction of links between the teaching-learning content to be discovered and the relevant elements to be observed: "tagged" spaces, positions and movements (Koekoek et al., 2018).

We therefore hypothesized that in condition 1, the STCs' content knowledge would move more quickly than in condition 2 towards the analysis of actions and interactions, integrating SMK, PCK and TPACK.

The use of the tablet would facilitate these interactions in the successive activities: cooperative practice (reduced game situations and matches), reciprocal teaching and visualization of the game (debates of ideas and interviews).

This digital tool would foster collective agreements on knowledge, decisions and strategies concerning the game and didactic choices.

Following the conclusions of Deenihan, Young and McPhail (2011), coaching would be led primarily by the STCs most experienced in team sports practice and teaching, who would transpose this experience to teach their classmates.

Thanks to this experience, these STCs would quickly decipher the faculty teacher's strategies and clues using the tablet. They would then use it to organize inquiry-based co-teaching in their team.

\section{Materials and methods}

\section{Participants and context}

Two groups $(n=48[24+24])$ of STCs were randomly assigned to the two conditions, balancing only for experience and level of practice in team sports and university results. The teaching module consisted of 12 futsal lessons lasting 1.5 hours each, all with the same pedagogical framework (reduced game situations, debates of ideas and matches). Some of the students had extensive experience playing football outside university. We refer to them as "experienced football players." The other students did more individual sports (such as gymnastics or athletics).

The faculty team chose futsal because it is not widely played by students outside university. The students discovered the specifics of this sport during the module, including its rules and teaching particularities, especially compared to football, which they were more familiar with. The faculty teacher was a football specialist (former player and high-level coach) and had taught futsal at the university for about 15 years. The lessons followed a weekly program common to both groups, but only the faculty teacher and the STCs in the first group (condition 1) used the tablets. No tablets were used for the second group (condition 2). The STCs were divided into teams as follows: 4x (5 players +1 substitute). The role of the substitute was only used in match situations. During a match, each player took turns as the substitute. The teams, which were of a similar level, remained the same and competed in each lesson. The faculty teacher brought together some or all of the 24 STCs to give instructions or suggest common rules of play several times during each lesson. 


\section{Data collection}

The lessons were recorded using two types of cameras equipped with microphones. The first camera was fixed. It used a wide-angle lens to film all the spaces used in the lesson (the pitch and discussion areas). The other cameras were mobile. They followed the teams as closely as possible in order to capture the interactions between the STCs and the faculty teacher.

We also conducted interviews with the faculty teacher and each of the STCs. The first interview was a semidirective pre-module or "pre-unit" interview (Verscheure \& Amade-Escot, 2007) with the faculty teacher. Prior to the lessons, he was asked about his teaching objectives, expectations and didactic intentions. The questions concerned the knowledge and content targeted at different moments during the module, his pedagogical approach and his teaching methods and tools. We also asked him for his teaching materials (written resources and curriculum for both himself and the STCs). A "post-module" interview (Verscheure \& Amade-Escot, 2007) conducted after the final lesson provided access to the faculty teacher's pedagogical and didactic assessment. During this interview, he was asked about the discrepancy between what he expected (initial teaching plan) and what was actually taught and learned. For this final interview, the faculty teacher was shown video sequences of teams from each of the two groups of STCs.

These videos were taken at two different times during the module: period 1, which was after the first half of the module (7th lesson out of 12), and period 2, which was at the end of the module (final matches and situations, lesson 12). The video sequences showed the evolution of STCs' acquisitions (content, game skills, didactic interactions, etc.) according to those initially targeted by the faculty teacher. They also showed the faculty teacher regulations that led to these developments.

To access the knowledge mobilized by the STCs during the lessons, we conducted individual self-confrontation interviews during the two periods identified above. That is, we conducted two interviews for each STC in both groups $(\mathrm{n}=96$ interviews $[2 \times 24+2 \times 24])$. We showed students wide-angle videos taken from the same video sequences as those shown to the teacher, as well as videos of other situations (reduced game situations, debates of ideas, reciprocal coaching) filmed during the same lessons. We questioned them on their thoughts, concerns, feelings, perceptions, decisions and intentions and then went on to questions about the technical, tactical, strategic and didactic dimensions of these decisions and intentions. For teaching and participation-related content, we also asked STCs about the basis for their choices and decisions in relation to the use of the digital tablet (for STCs in condition 1). They were asked to discuss this content in terms of game strategies and configurations as highlighted by the video sequences.

\section{Data processing and analysis}

Data was collected in the form of both videos and the transcriptions of verbal exchanges during lessons and interviews. This text was organized in table form. These tables specify the speaker and the context: interview or lesson; match or reduced game situations / debates of ideas / reciprocal coaching; period (1 or 2); condition (1 or 2); the player's position(s) within the team; STC team number; and experience with playing football.

We analyzed the discourse according to these parameters using the lexicometric tools in Alceste ${ }^{\circledR}$ software (Reinert, 2015). Thanks to a factorial correspondence analysis of the different words and associated speech classes, the words, classes and parameters entered in the software were identified as "modalities." Using top-down hierarchical classification (Reinert, 1993), we were able to assign a name to each of the lexical fields associated with the different discourse classes. The main words and associated parameters (listed below) could then be located within these classes. The classes are represented as shapes on the graph (Figure 1). In addition, thanks to the classification by networks within the classes, the software provides access to the associations between the terms making up the statements. Alceste ${ }^{\circledR}$ also offers the possibility to focus on the enunciative context of these terms at both sentence and paragraph levels.

Thanks to these areas of focus and synoptic representations, it is possible to clearly identify what the speakers focus on first (the discourse objects) and how they focus on those objects (through the expressions and turns of phrase used) according to the different contexts and moments. This offers a starting point for qualitative analyses of discursive strategies in situ. The enunciation strategies can therefore be interpreted as perlocutionary strategies (Austin, 1962). They are defined by the author as speech acts that have an effect on the listener, leading to someone acting in a certain way or making someone see something in the way the speaker intended.

Our complementary qualitative analyses (see below) considered these discursive strategies, including those involved during the lessons and in the comments addressed to the interviewer. We then analyzed the didactic specificity of discursive strategies during the module. This analysis concerns the mobilization of knowledge for practice, 

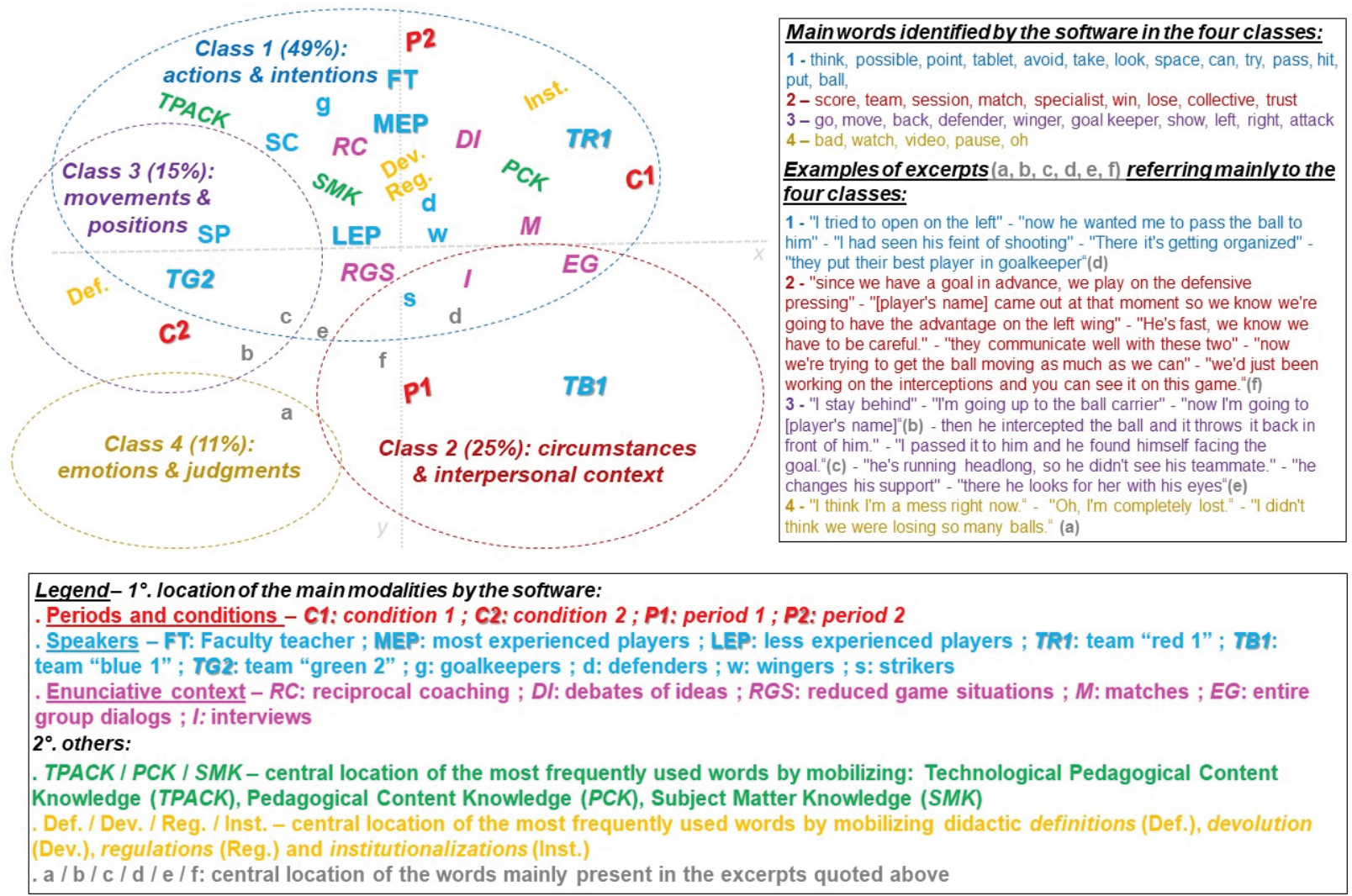

Figure 1. Factorial network adapted from the factorial correspondence analysis of the full textual data set Source: own study.

teaching and learning. The methodological tools used for this analysis are those traditionally used in the didactic tradition of physical education analysis (Amade-Escot, 2006).

Interviews and videos were used to identify the didactic strategies and contextualize their use. The analysis of didactic strategies then focused on language interactions and, in particular, on the teaching utterances collected at the corresponding sentence level within the following categories: questions, explanations and justifications, pointing out actions and spaces, requests to act, judgments of actions made, observations and proposing alternatives. These categories are based on those proposed by Brière-Guenoun and Musard (2019) in order to then interpret the structure of STs' teaching action in didactic interactions. These interpretations use the quadruplet method of defining, devolving, regulating and institutionalizing to structure the didactic action (Sensevy et al., 2005).

Using this categorization method, it is possible to identify how the faculty teacher and the STCs define what needs to be done to engage the STCs in situations (devolution), regulate their activity and commitment and, finally, officially recognize the targeted knowledge and content (institutionalization). This interpretive method enables us to show how SMK, PCK and TPACK are mobilized within the teaching-learning process. These categories of didactic knowledge and actions are therefore located on the diagram in Figure 1.

\section{Results}

In this section, we present the lexicometric results and the results of the didactic analysis of the interactions between the STCs. Finally, we analyze the impact of the teaching project and faculty teacher regulations on these interactions.

\section{Mobilized knowledge: Contributions of the lexicometric analysis}

The factorial correspondence analysis applied to the full textual data set (transcribed speech) divides four categories of discourse into two axes of dialectical tension, named after the top-down hierarchical classification. The horizontal axis (x), represents the tension between "local and observable" (on the left) and "general and conceptual" 
(on the right). On the vertical axis (y), "judgments in context" (at the bottom) are opposed to "intentional logic of actions" (at the top).

The top-down hierarchical classification (excerpt in Figure 2) also names and characterizes the classes according to the contents of the text that the software associates with them. The most common terms in each class are shown in Figure 1.

Figure 2 shows an excerpt from the top-down hierarchical classification. This excerpt allows us to illustrate the lexical links or "bridges" (Reinert, 1993) between the classes articulated within the text.

Class 4, "emotions and judgments," is more present in condition 2 and in period 1. It displays the negative emotions and judgements expressed during the reactions of the STC when they see themselves on video (Excerpt a, Figure 1) or when they play. Located at the bottom left of the factorial correspondence analysis, it includes judgments about game and player qualities (adjectives, adverbs), interjections and interpellations (imperative verbs) during lessons and while

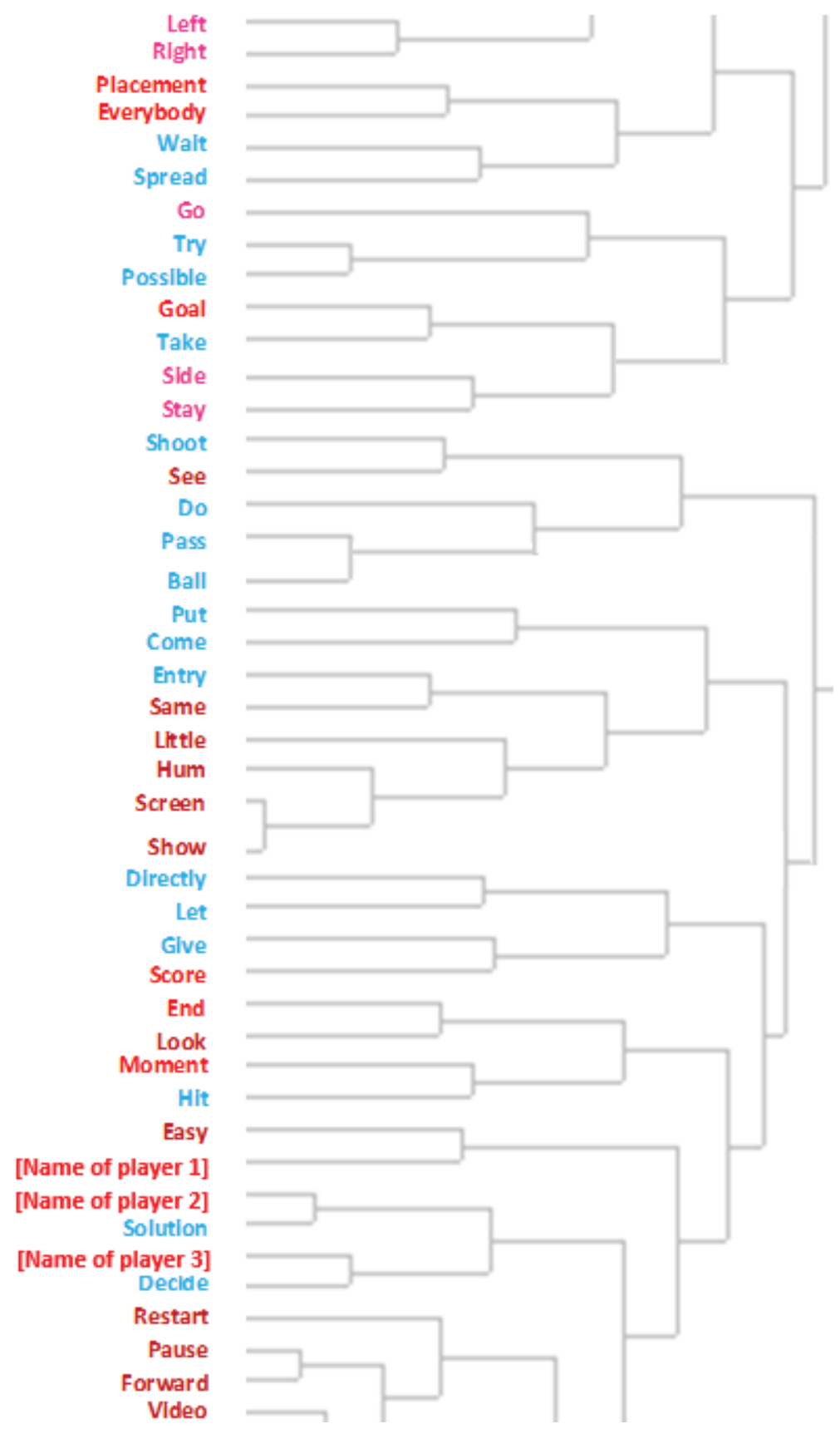

Figure 2. Extract from the top-down hierarchical classification applied to the total textual data set Source: own study. 
watching the videos. Class 2, located at the bottom right of the factorial correspondence analysis, essentially contains common nouns. Mostly occurring during the interviews, in condition 2 and at time 1, this class expresses the "circumstances and interpersonal context" of actions during play (such as a moment in the training module, score, match, balance of power; see Excerpt f, Figure 1). Both appraised (class 4) and contextualized (class 2), these actions refer more to "movements and positions" (class 3 ) in condition 1 and period 2. Class 3 thus features analysis of observed actions during play and corresponding player activities, which is more prevalent among experienced football players during reciprocal coaching with the use of tablets (Excerpts b, c and e, Figure 1). Analysis is more strategic and intentional in the typical comments in class 1 ("actions and intentions"; see Excerpt d, Figure 1). The prevalence of analysis increases at the end of the module, especially during the debates of ideas. Analysis occurs primarily in the comments by the faculty teacher and by the experienced football players, and more broadly in condition 1 .

Comments by players on the same team tend to converge around the same coordinate $(\mathrm{x}, \mathrm{y})$ on the factorial correspondence analysis from period 1 to period 2, confirming the hypothesis of the construction of a team culture (e.g., team "blue[condition] 1" in class 2 and team "red[condition] 1" in class 1; see Figure 1). This case, and those of the other teams in condition 1, confirms the hypothesis of the impact of tablets on STCs agreeing on choices, making decisions (mainly in debates of ideas and reciprocal coaching) and analyzing (mainly in debates of ideas and self-confrontation interviews). The convergences observed from one period to the next are at the top right of the diagram (factorial correspondence analysis, Figure 1). This trend reflects a conceptualization of the practice of futsal and the conditions for its effectiveness. This fosters the mobilization and articulation of content to learn to teach (PCK), play (SMK) and use the tablet for educational purposes (TPACK). The classification (top-down hierarchical classification) thus helps to identify how, over the course of the module, the lexical bridges between classes reflect this ability to conceptualize content. The extract from Figure 2 includes words whose identification makes it possible to see how, from one period to another, the STCs manage to rely on the observation of team players and overcome the judgments and emotions felt at the time (class 4) while analyzing the context of the situation (e.g., "placement" conditions - class 2). This contextualization is used to access the meaning of actions and movements (class 3). This meaning is enriched by linking actions, decisions, intentions and associated game configurations (class 1). The STC can then envisage possible and desirable developments in the activity and game; for example, according to specific futsal principles (SMK). The conditions of these evolutions are at the heart of the PCK (e.g., how to teach a rule) and TPACK (e.g., how to get people to see a configuration in certain a way).

\section{Analysis of interactions and teaching strategies}

\section{Interactions between STCS}

The table below is based on the categories used to analyze the didactic dimensions of the comments made during these interactions.

Table 1. Categorization of didactic strategies in interactions.

\begin{tabular}{lcccc}
\hline & \multicolumn{2}{c}{ Condition 1 } & \multicolumn{2}{c}{ Condition 2 } \\
\hline & Period 1 & Period 2 & Period 1 & Period 2 \\
\hline Questions asked (1) & + & ++ & - & + \\
Explanations and justifications (2) & + & - & - & + \\
Pointing out actions and spaces (3) & + & ++ & - & + \\
Requests to act (4) & + & - & + & ++ \\
Judgments on actions made (5) & ++ & + & - & ++ \\
Making observations (6) & + & ++ & - & + \\
Proposing alternatives (7) & + & ++ & & + \\
\hline
\end{tabular}

Source: own study.

This table shows categories ranging from highly present (++) to rarely present (-) in the comments of the STCs, mainly driven by the experienced football players. Those in condition 1 questioned their teammates (1) more than those in condition 2 and used the tablet to point out actions and spaces (3) in order to help construct observations 
(6) and suggest new alternatives of actions based on those initially proposed (7). In condition 2, the STCs were less inclined to encourage these proposals. From one period to another and in contrast to condition 1, they were more committed to normative judgements (5) by justifying (2) their requests to act (4). In summary, from one period to the next, each group moved towards different pedagogical strategies during co-teaching: inquiry of teammates (condition 1) versus directivist pedagogy (condition 2).

During the lessons, almost all the experienced football players took on the role of coach and captain of their team. Their comments mobilized the most PCK and TPACK (especially during self-confrontation interviews; e.g., "They have to go back to the center of the pitch faster after passing behind the opponent's back" or "I'm showing the game corridor"). They engaged in tutoring relationships with their teammates. These teammates often described their play with reference to their team's tactical and strategic choices (e.g. "We chose to keep the game as far away as possible" and "Now we can see that we don't hesitate to switch," from the SCT interviews). Their comments were more about their tactical learning (in relation to SMK) than about didactic interactions and learning to teach futsal.

During the self-confrontation interviews, the experienced football players described their teaching strategies using the tablet (condition 1). The tablet was used during the module to designate (period 1) and then to introduce (period 2) the expected configurations, solutions and game actions. Finally, the experienced football players regulated the use of the tablets by their teammates, especially during the debates of ideas. They sought to orient their reasoning and proposals by guiding them and questioning them on their choices and analyses using words such as "Don't you think we could try to...?" and "What do you think of the use of this space?" or "What's the problem here?" as well as "What would you advise, [name of the player]?" Experienced football players thus regulated the learning and teaching process of non-experienced football players. The faculty teacher also used these strategies, especially in condition 1, to clarify his expectations and then deliver clues to help discover useful elements for playing, learning and teaching. That said, this strategic transformation happened more quickly for the faculty teacher than for the experienced football players.

In condition 1 matches, after a few lessons, the experienced football players played the role of defender or goalkeeper to observe and direct the game from a "diamond" game tactical organization: one goalkeeper, one defender, two wingers and one attacker. They then used a lot of deictics (e.g., "here" and "there") and imperative verbs (e.g., "Look!" and "Go!") while coaching and took charge to foster tactical regulation and debates of ideas consisting of numerous exchanges. Didactic needs (observing to facilitate teaching) therefore had an impact on the organization of the game and on interactions. On the other hand, in condition 2, the majority of teams chose a "square" organization (one goalkeeper, two defenders and two forwards). They chose the "diamond" organization later in the module. Regulations and exchanges (reciprocal coaching, debates of ideas) were less common than in condition 1 and remained shorter, more general and allusive. They were based on the faculty teacher's comments, sometimes regardless of the problems actually encountered while playing.

\section{Teaching project, analysis and regulations of the faculty teacher; impact on content studied and taught by the STCs}

The faculty teacher aimed to adapt training curriculum designed by the French Football Federation (FFF) on a series of themes (conservation, progress and transition) structured one lesson after another. The situations described in the curriculum (reduced game situations, for the most part) included diagrams of the positions and movements of the players and the ball on the pitch (and the equipment), objectives, instructions (rules to be respected), performance criteria (what to do) and possible variables (complexification, simplification).

In the first lessons, the STCs had to achieve what the faculty teacher asked of them by presenting each situation. The faculty teacher then questioned them later in the module about the main problem this situation posed and how to solve it. This usually involved identifying the requirements and constraints that are typical in a game configuration. The objective was to make the right decisions for the team to progress. During the first two lessons, the debates of ideas were short, with the faculty teacher providing solutions quickly. He described this pedagogy as directivist (post-module interview).

Then, during the third lesson, he offered different alternatives for STCs to discuss. From the eighth lesson onwards, it was the STCs who had to identify problems, alternatives and optimal solutions. Exchanges between STCs then developed around how to best "open" effective game spaces when attacking and how to "close" them in defense (STCs, debates of ideas, lesson 9). These were the main subjects of SMK teaching addressed by the faculty teacher. The STCs then discussed ways to "recover the ball as soon as possible" "after the goalkeeper's throw-ins" (id.) in order to give themselves time to optimize the space, which is specific to futsal compared to football. Another distinction (the absence of the offside rule) meant that the STCs took an interest in managing the space in the width 
of the pitch as the ball progressed in order to "go behind the defense" (a common comment from the STCs and the faculty teacher in interviews).

This space management was not explicitly addressed in the faculty teacher's lessons, but he identified progress at this level (post-module interview), particularly for the STCs in condition 1. The faculty teacher identified the "increased capacity" of the STCs in this group to "switch their roles in the game if necessary." He said that the tablet had allowed them to "focus more on the spaces and game configurations than on their initial roles as players." He also noted that the tablet "facilitates the overall vision of the game" thanks to the "tagging" software (Dartfish ${ }^{\circledR}$ ), which the STCs quickly learned to use by observing how the faculty teacher used it in the first lesson.

The faculty teacher (post-module interview) noted the transition from a "game of individual counter-attacks" (tendency in period 1) to a "game of passes and collective exploitation of the spaces and opportunities" (tendency in period 2) offered and created in teams equipped with tablets who thus accessed the overall vision of the game more easily. The technological use of the tablet thus facilitated access to tactical and strategic knowledge at the heart of the SMK involved in this team sport. STCs were therefore able to invest this knowledge in constructing PCK, especially during the debates of ideas.

\section{Discussion and conclusions}

This study aimed to investigate how the knowledge to learn to play and teach futsal was mobilized during a teaching module at a university. The results demonstrated that this mobilization depended on the roles (player, coach and teacher) and that it was impacted by the strategies for using the digital tablet in collaborative situations. The faculty teacher began by using the tablet to explicitly show and name what needed to be done according to highlighted configurations by "tagging" "relevant events" (Koekoek et al., 2018, p. 13).

Later in the module, it was up to the students to recognize these events and configurations according to the clues tagged by the faculty teacher. Then, they chose the videos themselves, which they could tag to decide what was important to see, do and know by identifying and selecting teaching and learning content. The acquisition of a better game sense (Launder \& Piltz, 2013) through working independently with the tablet (Koekoek et al., 2018) does not only concern the collective practice of sport. The results suggest that this acquisition is a lever for the acquisition of a broader didactic game (Sensevy, 2014) facilitated by the tablet (condition 1). The sense of the didactic game refers to the ways of interacting to foster the appropriation of content useful for learning to play and learning to teach. Thus, the principle of devolution (Brousseau, 1997) is illustrated here by the ability of the faculty teacher, and then the experienced football players, to facilitate the STCs' investigations without depriving them of their investigative activity by giving them useful clues. This could explain the didactic reticence (Sensevy, 2014) to offer prior solutions to the problems posed by learning situations and/or identified using tablets. This reticence was noted after a few lessons with the faculty teacher and then among experienced football players.

This principle is only possible once students have previously acquired a common grammar of actions and language (Wittgenstein, 1953/2001), resulting in a more explicit first phase of teaching (see above). The didactic skills of students were therefore acquired as they understood first the nature of the clues on which to base effective action as players and then the reasoning behind providing such clues in ways which devolve and regulate problem construction and resolution related to learning and teaching among their classmates. Thus, in condition 1, the PCK was constructed from the SMK in connection with the TPACK: devolution concerned the use of the tablet for didactic purposes, which ultimately allowed inexperienced football players to use it to teach. Devolution seemed to be acquired over time through mimicry and experimentation with didactic strategies, from the faculty teacher to experienced football players and then from experienced football players to inexperienced football players. This shows that access to PCK and TPACK first requires thorough knowledge of the contents at stake in the SMK.

The tablet had an impact on the construction of knowledge mobilized in learning and teaching activities thanks to the way it allowed these activities to be staged. It enhanced the visibility of play and of didactic intentions to improve learning and teaching. The collaborative practice curricula for students in sports science (e.g., learning together to teach by learning to play; Deenihan, Young, \& McPhail, 2011) therefore directly benefit from being designed in a way that organizes the visibility of didactic objects and intentions. In this sense, we recommend that the stages of appropriation of digital tools be integrated within the practical modules of sports science at universities in order to structure their use. The main limitation of this study and a limitation for the application of this recommendation is that it did not deepen the link between the acquisition of playing and teaching skills. Future work should therefore include an analysis of the evolution of the motor and perceptual-decisional activity of the STCs. This would allow us to understand the 
connection between the different strategies and comments more fully. This would help design the steps of a curriculum integrating digital uses according to the specificity of the content and skills targeted over time (Tricot \& Sweller, 2014), including digital teaching skills. According to the recommendations of the Council of Europe (2019), educational projects should encourage the use of digital technology rather than being driven by the technology itself. The stakes are high in the context of university and school education policies considering the current educational needs of a world where the joint development of digital, social and professional skills is increasingly challenging.

Some of our results question the conditions of this joint development. Indeed, the devolution of the identification of knowledge to be taught and knowledge that is useful for teaching did not lead the faculty teacher to organize in-depth group discussions on the content of these kinds of knowledge and how they should be articulated in order to improve teaching. Without denying the interest of the freedom of choice left to the STCs concerning the strategies and objects taught, we recommend that the strategies of knowledge devolution be more explicitly worked on as a training object in the sports science curricula. Their tacit integration within the PCK of STCs through imitation of the faculty teacher seems insufficient to us. This study also showed that without the use of the tablet, the devolution strategies of the faculty teacher were made less visible to STCs, who in turn identified fewer knowledge objects to be devolved (condition 2). This reduced the opportunities for all STCs to think about their teaching strategies by integrating the conditions of their classmates' investigation of the problems posed by the situation. We note that the development of joint attention (Eilan et al., 2005) requires paying attention to the object of others' attention (Sensevy, 2014). Debates of ideas foster access to these objects. They could offer an opportunity to make the teaching strategies and choices more explicit to all the STCs. Studying video extracts of debates of ideas linked to game episodes as a whole group would allow the faculty teacher to organize a shared reflection on the effective conditions for devolution and regulation of learning according to the needs and requirements of the STCs. It would be a sort of joint anthropological investigation into the construction of each STC's practical and educational expertise, in line with Ingold's (2017) idea that anthropology and education are both ways of studying and living with others.

In this way, it would be possible to avoid the disparities in knowledge and skills between the teams observed in this study, such as strategic choices and role distribution patterns whose ineffectiveness the STCs found difficult to identify (especially in condition 2). The challenge is to ensure that students can build and experience an effective practice, teaching and learning project together. At a time of increasing individualization of training courses in schools and universities, this recommendation seems to us to be essential for the construction of a shared culture.

\section{Ethics approval and informed consent}

The study was approved by the ethics committee of the authors' research group.

\section{Competing interests}

There is no conflict of interest in this study.

\section{Funding}

This research was funded by the Armorican Research Group on the Information Society and the Uses of the Internet.

\section{Acknowledgments}

We thank the students and fellow teachers who made this study possible.

\section{References}

Almeida, C., Ferreira, A., \& Volossovitch, A. (2013). Offensive sequences in youth soccer: Effects of experience and small-sided games. Journal of Human Kinetics, 36(1), 97-106.

Amade-Escot, C. (2006). Student learning within the didactique tradition. In D. Kirk, M. O’Sullivan, \& D. Macdonald (Eds.), Handbook of Research in Physical Education (pp. 347-365). Thousand Oaks, CA: SAGE Publications Ltd.

Armour, K.M. (2011). What is "sport pedagogy" and why study it? In K. Armour (Ed.), Sport Pedagogy: An Introduction for Teaching and Coaching (pp. 11-24). London, UK: Pearson.

Austin, J. (1962). How To Do Things with Words. Oxford, UK: Oxford University Press.

Brière-Guenoun, F. \& Musard, M. (2019). Didactic analysis of the activity of students in $3^{\text {rd }}$ year of bachelor's degree in sports science. In G. Escalié \& É. Magendie (Eds.), Integrative Alternation and Teachers' Education (pp. 39-59) [translated]. Bordeaux, France: Bordeaux University Press. 
Brousseau, G. (1997). Theory of Didactical Situations in Mathematics. Dordrecht, Netherlands: Kluwer Academic Publishers.

Carlson, T. B. (1995). "Now, I think I can." The reaction of eight low-skilled students to sport education. ACH-PER Healthy Lifestyles Journal, 42(40), 6-9.

Cross, D. (2010). Joint action and professional knowledge of the teacher [translated]. Education et didactique, 4-3, 39-60.

Carter, K. (1990). Teachers' knowledge and learning to teach. In W. R. Houston \& M. H. J. Sikula (Eds.), Handbook of Research on Teacher Education, (pp. 291-310). New York, USA: Macmillan.

Castagna, C., D’Ottavio, S., Vera, J. G., \& Álvarez, J.C.B. (2009). Match demands of professional futsal: A case study. Journal of Science \& Medicine in Sport, 12(4), 490-494.

Cochran, K., DeRuiter, J., \& King, R. (1993). Pedagogical content knowing: An integrative model for teacher preparation. Journal of Teacher Education, 44(4), 263-271.

Collier, C. (1998). Sport education and preservice education. The Journal of Physical Education, Recreation \& Dance, 69(5), 44-45.

Council of Europe. (2019). Digital Citizenship Education Handbook. Strasbourg, France: Council of Europe Publishing.

Deenihan, J. T., McPhail, A., \& Young, A.-M. "Living the curriculum”: Integrating sport education into a physical education teacher education programme. European Physical Education Review, 17(1), 51-68.

Eilan, N., Hoerl, C., McCormack, T., \& Roessler, J. Joint Attention: Communication and Other Minds. Oxford, UK: Oxford University Press.

European Parliamentary Research Service. (2020). Rethinking education in the digital age. Brussels, Belgium: European Parliamentary Research Service.

Fonseca, S., Milho, J., Travassos, B., \& Araújo, D. (2012). Spatial dynamics of team sports exposed by voronoi diagrams. Human Movement Science, 31(6), 1652-1659.

Fuller, F. F. \& Manning, B. A. (1973). Self-confrontation reviewed: A conceptualization for video playback in teacher education. Review of Educational Research, XLIII, 4, 469-528.

Frencken, W., et al. (2013). Size matters: Pitch dimensions constrain interactive team behaviour in soccer. Journal of Systems Science and Complexity, 26(1), 85-93.

Geisler, G. \& Kerr, J. H. (2007). Competition stress and affective experiences of Canadian and Japanese futsal players. International Journal of Sport Psychology, 38(2), 187-206.

Gillies, R. \& Ashman, A. (1996). Teaching collaborative skills to primary school children in classroom-based work groups. Learning and Instruction, 6, 187-200.

Gréhaigne, J-F., Richard, J-F., \& Griffin, L. (2005). Teaching and Learning Team Sports and Games. London, UK: Routledge-Falmer.

Gomes, A. R., Pereira, A. P., \& Pinheiro, A. R. (2008). Leadership, cohesion and satisfaction in sporting teams: A study with Portuguese football and futsal athletes. Psicologia: Reflexao e critica, 21(3), 482-491.

Guskey, T. (1988). Teacher efficacy, self-concept, and attitudes toward the implementation of instructional innovation. Teaching and Teacher Education, 4(1), 63-69.

Hastie, P. A. \& Curtner-Smith, M. D. (2006). Influence of a hybrid Sport Education - Teaching Games for Understanding unit on one teacher and his students. Physical Education and Sport Pedagogy, 11(1), 1-27.

Ingersoll, C., Jenkins, J.-M., \& Lux, K. (2014). Knowledge development in early field teaching experiences. Journal of Teaching in Physical Education, 33, 363-382.

Ingold, T. (2017). Anthropology and/as Education. London, UK: Routledge.

Joffredo-Le Brun, S., Morelatto, M., Sensevy, G., \& Quilio, S. (2018). Cooperative engineering in a joint action paradigm. European Educational Research Journal, 17(1), 187-2018.

Kagan, D. M. (1992). Professional growth among preservice and beginning teachers. Review of Educational Research, 62(2), 129-169.

Kinchin, G. D., Penny, D., \& Clarke, G. (2005). Sport education in teacher education. In D. Penny, G. Clarke, M. Quill, \& G.D. Kinchin (Eds.), Sport Education in Physical Education: Research-Based Practice. (pp. 217-228). Routledge.

Koehler, M. J. \& Mishra, P. (2009). What is technological pedagogical content knowledge? Contemporary Issues in Technology and Teacher Education, 9, 60-70.

Koekoek, H., van der Mars, H., van der Kamp, J., Walinga, W., \& van Hilvoorde, I. (2018). Aligning digital video technology with game pedagogy in physical education. Journal of Physical Education, Recreation and Dance, 89(1), $12-22$.

Launder, A. G. \& Piltz, W. (2013). Play practice: Engaging and developing skilled players from beginner to elite. Champaign, USA: Human Kinetics. 
Magnusson, S., Krajcik, L., \& Borko, H. (1999). Nature, sources and development of pedagogical content knowledge. In J. Gess-Newsome \& N. G. Lederman (Eds.), Examining Pedagogical Content Knowledge (pp. 95-132). Dordrecht, Netherlands: Kluwer Academic Publishers.

Moore, R., Bullough, S., Goldsmith, S., \& Edmonson, L. (2014). A systematic review of futsal literature. American Journal of Sports Science and Medicine, 2(3), 108-116.

Moreira, V.J.P., Da Silva Matias, C.J.A., \& Greco, P.J. (2013). Motriz. Revista de Educacao Fisica, 19(1), 84-98.

Nespor, J. (1987). The role of beliefs in the practice of teaching. Journal of Curriculum Studies, 19(4), 317-328.

Olofson, M. W., Swallow, M. J. C., \& Neumann, M. D. (2016). TPACKing: A constructivist framing of TPACK to analyze teachers' construction of knowledge. Computers \& Education, 95, 188-201.

Oslin, J., Collier, C., \& Mitchell, S. (2001). Living the curriculum. Journal of Physical Education, Recreation \& Dance, 72(5), 47-51.

Polidoro, L., Bianchi, F., Di Tore, P.A, \& Raiola, G. (2013). Futsal training by video analysis. Journal of Human Sport \& Exercise, 8(2), 290-296.

Reinert, M. (2015). Alceste [computer software]. Toulouse, France: Image.

Reinert, M. (1993). The "lexical worlds" and their "logic" through the statistical analysis of a corpus of nightmare stories [translated]. Langage \& Société, 66, 5-39.

Rollnik, M. \& Mavhunga, E. (2016). The place of subject matter knowledge in teacher education. International Handbook of Teacher Education, 1, 423-452.

Rollnick, M., Bennett, J., Rhemtula, M., Dharsey, N., \& Ndlovu, T. (2008). The place of subject matter knowledge in pedagogical content knowledge: A case study of South African teachers teaching the amount of substance and chemical equilibrium. International Journal of Science Education, 30(10), 1365-1387.

Rowan, B., Schilling, S.G., Ball, D., \& Miller, R. (2001). Measuring teachers' pedagogical content knowledge in surveys: An exploratory study. Consortium for Policy Research in Education, University of Pennsylvania.

Sargent, J. (2018). Exploring pedagogy and digital technology in physical education through appreciative inquiry. $\mathrm{PhD}$ thesis, Loughborough University, Loughborough, UK.

Schön, D. A. (1983). The Reflective Practitioner. New York, USA: Basic Books.

Schön, D. A. (1987). Educating the Reflective Practitioner: Toward a New Design for Teaching and Learning in the Professions. San Francisco, USA: Jossey-Bass.

Sensevy, G. (2014). Characterizing teaching effectiveness in the joint action theory in didactics: An exploratory study in primary school. Journal of Curriculum Studies, 46(5), 577-610.

Sensevy, G., Mercier, A., Schubauer-Leoni, M-L., Ligozat, F., \& Perrot, G. (2005). An attempt to model the teacher's action in the mathematics class. Educational Studies in Mathematics, 59, 153-181.

Shulman, L. (1986). Those who understand: Knowledge growth in teaching. Educational Researcher, 15(2), 4-14.

Stein, M. K. \& Wang, M. C. (1988). Teacher development and school improvement: The process of teacher change. Teaching and Teacher Education, 4, 171-187.

Storchevoy, N.F., Belikov, E.M., Maksimenko, A.V., \& Smekhunov, A.A. (2013). Mini-futbol kak sredstvo professional'noprikladnoj fiziceskoj podgotovki studentov techniceskich. vuzov. Teoriya I Praktika Fizicheskoy Kultury, 9, 38-40.

Stran, M. \& Curtner-Smith, M. (2010). Impact of different types of knowledge on two preservice teachers' ability to learn and deliver the sport education model. Physical Education and Sport Pedagogy, 15(3), 243-256.

Travassos, B., Arauújo, D., Davids, K., Esteves, P. T., \& Fernandes, O. (2012). Improving passing actions in team sports by developing interpersonal interactions between players. International Journal of Sports Science \& Coaching, 7(4), 677-688.

Tricot, A. \& Sweller, J. (2014). Domain-specific knowledge and why teaching generic skills does not work. Educational Psychology Review, 26, 265-283.

Verscheure, I. \& Amade-Escot, C. (2007). The gendered construction of physical education content as the result of the differentiated didactic contract. Physical Education and Sport Pedagogy, 12(3), 245-272.

Wallhead, T. \& Dyson, B. (2016). A didactic analysis of content development during cooperative learning in primary physical education. European Physical Education Review, 23(3), 1-16.

Webb, M. \& Cox, M. (2004). A review of pedagogy related to information and communications technology. Technology, Pedagogy and Education, 13(3), 235-286.

Wittgenstein, L. (1953/2001). Philosophical Investigations. Hoboken, USA: Blackwell Publishing.

This is Open Access article distributed under the terms of CC-BY-NC-ND 4.0 International License. 